\title{
Plant pigments as pH indicators in cooking
}

\section{Heli Motturi}

Akaan lukio, Akaa, Finland • heli.motturi@akaa.fi

\section{Sari Slawuta}

Hirvialhon koulu, Akaa, Finland • sari.slawuta@akaa.fi

\section{Sirpa Salkunen}

Etelä-Hervannan koulu, Tampere, Finland • sirpa.salkunen@koulut.tampere.fi

\section{Petra Rajala}

Etelä-Hervannan koulu, Tampere, Finland • petra.rajala@koulut.tampere.fi

Controlling acidity comes up often during cooking. Food's acidity can be discussed in connection to using vinegar, marinade or baking soda in cooking. One seldom considers that acidity affects the food's colour and thus its appeal. Colour is especially significant for ready-made foods. Berry jam or juice that is too pale or too dark does not look fresh or appealing. Many of the foods that lose their colour easily contain nature's own $\mathrm{pH}$ indicators, anthocyanins. The workshop detailed in this article explores discolouration of anthocyanins with the help of different methods. Anthocyanins offer many points of discussion for chemistry classes, because in addition to their indicator properties, anthocyanins are also flavonoids and food additives. The work instructions are mainly aimed at grades 7 to 9 . The chemistry part involving anthocyanins is suitable for upper secondary school as well, since it is challenging. The article details a demonstration that motivates towards inquiry-based work and two alternative work instructions.

\section{Aim of the workshop}

The work aims to introduce the students to concepts of acidity and indicators through food. The national core curriculum identifies the concepts acidity and basicity as key contents in 7th - 9th grade chemistry education; these concepts can be explored with the help of indicators. Anthocyanins are natural indicators.

Nutritional guidelines, healthy food and food quality and safety are emphasised in the home economics materials. Use of anthocyanins as food additives is closely related to these materials. The food additive use of anthocyanins can also be discussed in chemistry classes. In home economics, the subject might be best discussed when dealing with additives in general, either in 8th or 9th grade.

\section{Experimental part}

\subsection{Motivational opening demonstration}

In the motivational opening demonstration, lemonade is poured in transparent glasses. Different substances that alter the lemonade's acidity are placed in glasses beforehand. The reddest, the most acidic, drink contains hydrochloric acid $(\mathrm{HCl})$ and the yellowest sodium 
hydroxide $(\mathrm{NaOH})$ (Figure 1). The other colours are achieved with different amounts of baking soda $\left(\mathrm{NaHCO}_{3}\right)$. Acidity in the glasses varies between $\mathrm{pH} 1 \ldots \mathrm{pH} 11$. The drinks are of course undrinkable, but the colours can be used to initiate discussion. The reddest and most acidic drink is made with hydrochloric acid and the yellowest with sodium hydroxide. The other colours are achieved with baking soda. Students should try to answer:

- What drink has the most appealing colour?

- What could be the cause of discolouration?

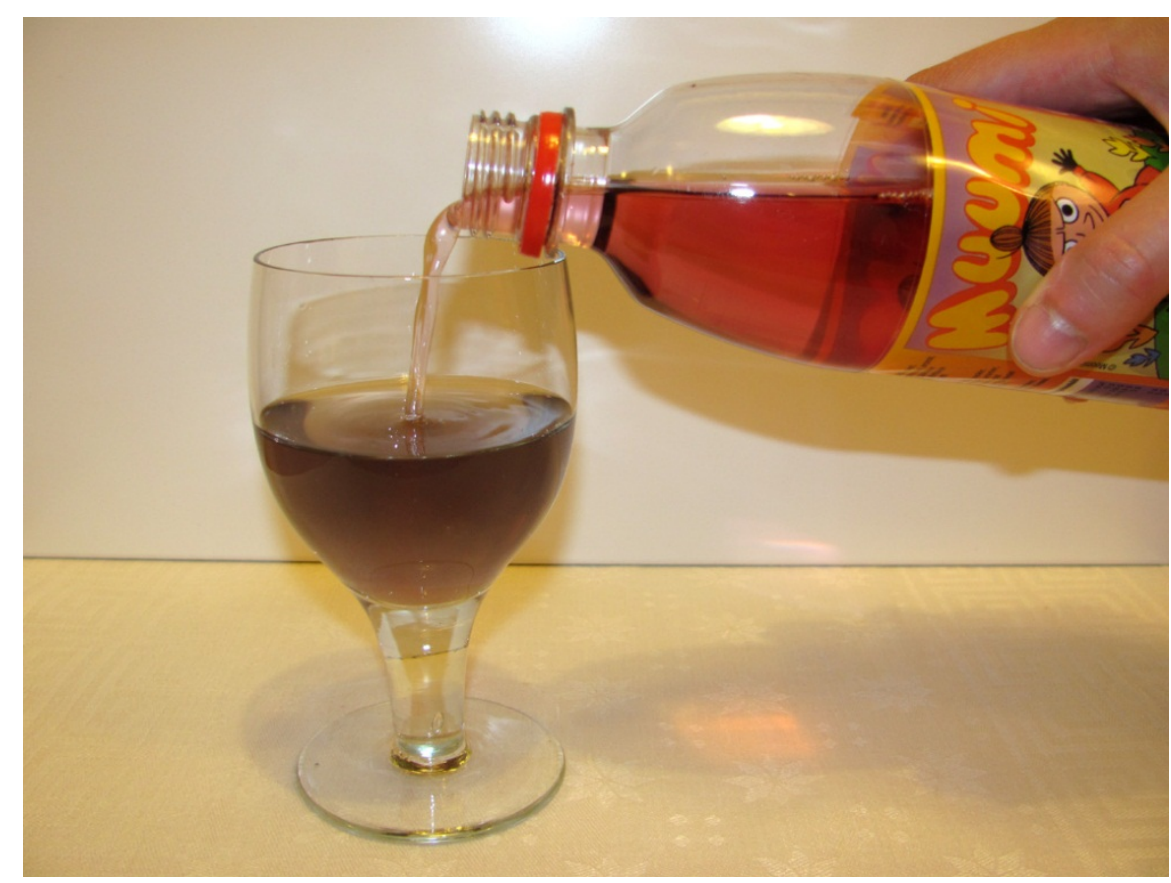

Figure 1. Lemonade of unusual colour.

\subsection{Inquiry-based work 1: Different colour meringues}

The inquiry-based work can be performed in 8th or 9th grade chemistry or optional home economics double class $(2 \times 45 \mathrm{~min})$. This inquiry-based work teaches how to make egg white foam and how a change in the egg white $\mathrm{pH}$ affects the colour of blueberry. Blueberry contains anthocyanins that act as natural indicators.

Students in the teaching group can work in pairs. One pair prepares meringues of just one colour: white, blue or red. Each pair should be given separate recipes and reminded to follow them. There is no reason to do what another pair is doing as their recipe can be different.

Before beginning, it is wise to go over how to separate the egg white and yolk. In order to successfully make meringue, it is important not to mix yolk with the whites and to make sure that the whisking equipment is not greasy. Fat can interfere with and even prevent the egg white foam formation (Vilhunen, 2012). A glass or steel bowl is better than a plastic 
bowl because fat sticks to plastic more easily even after washing. Even though water does not prevent the foam from forming, students should be told to use clean and dry whisking equipment (bowls and whisks). The end results can be compared by observing and tasting them after cooking.

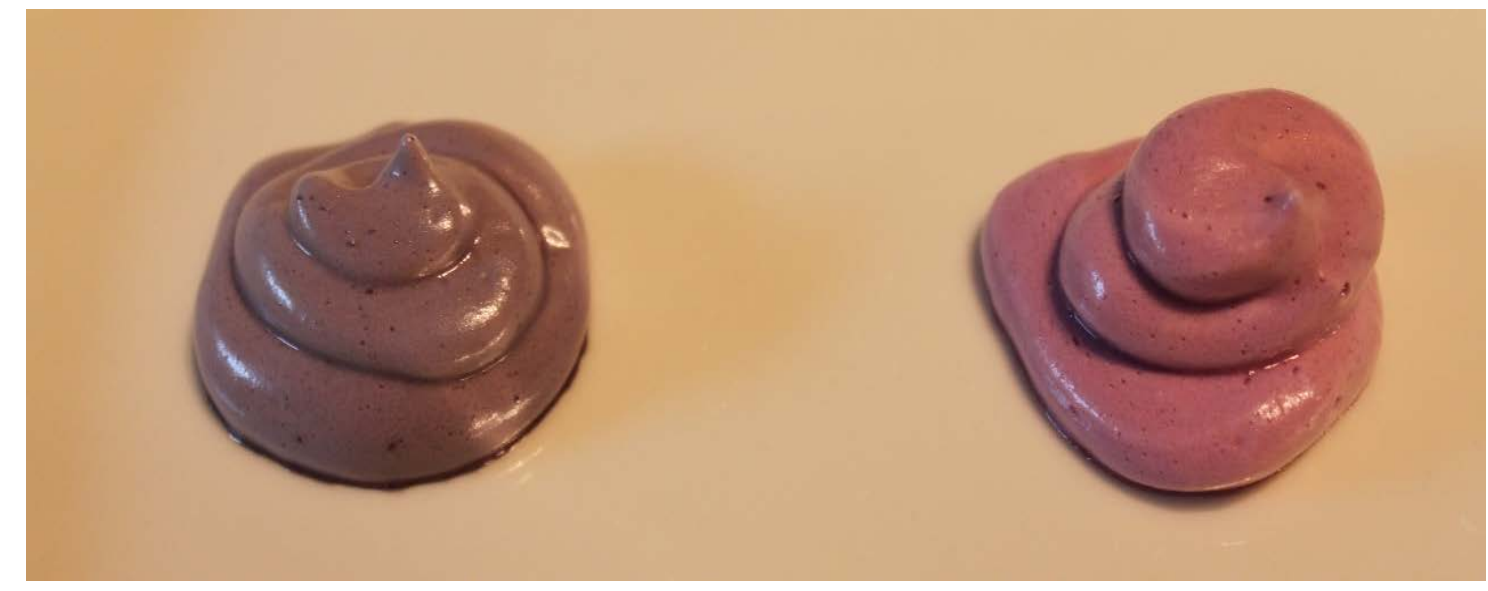

Figure 2. Blue meringues before cooking.

\section{White meringues (4 servings)}

Utensils:

- bowl, whisks, mixer, $1 \mathrm{dl}$ measuring cup, indicator paper, pastry bag, baking tray and parchment paper, pen

Ingredients:

- egg white

- $3 / 4 \mathrm{dl}$ icing sugar

Method:

1. Determine the white's $\mathrm{pH}$ with indicator paper. The egg white $\mathrm{pH}$ is

2. Whisk the white into stiff foam with a mixer. Sprinkle in icing sugar near the end of whisking. Continue whisking while sprinkling.

3. Determine the prepared meringue foam's $\mathrm{pH}$ with indicator paper. The prepared meringue foam $\mathrm{pH}$ is

4. Pipe the meringues on the tray.

5. Cook the meringues in an oven at low temperature (approximately $60^{\circ} \mathrm{C}$ ), until they are dry and come off the parchment paper.

Additional information for the teacher:

Egg white's $\mathrm{pH}$ was 10 in the model work. When the white was whisked the $\mathrm{pH}$ decreased ( $\mathrm{pH}$ 8). The $\mathrm{pH}$ of eggs varies and depends on the age of the egg: older eggs are more basic. 


\section{Blue meringues (4 servings)}

Utensils:

- bowl, whisks, mixer, $1 \mathrm{dl}$ measuring cup, 1 tablespoon measuring cup, indicator paper, pastry bag, baking tray and parchment paper, pen

Ingredients:

- egg white

- $3 / 4$ dl icing sugar

- $15 \mathrm{ml}$ (3 tbsp.) blueberry juice

Method:

1. Determine the white's $\mathrm{pH}$ with indicator paper. The egg white $\mathrm{pH}$ is

2. Whisk the white into stiff foam with a mixer. Sprinkle in icing sugar near the end of whisking. Continue whisking while sprinkling.

3. Add blueberry juice to prepared meringue foam.

4. Determine the prepared meringue foam's $\mathrm{pH}$ with indicator paper. The prepared meringue foam $\mathrm{pH}$ is

5. Pipe the meringues on the tray.

6. Cook the meringues in an oven at low temperature (approximately $60{ }^{\circ} \mathrm{C}$ ), until they are dry and come off the parchment paper.

Additional information for the teacher:

$15 \mathrm{ml}$ of juice squeezed from blueberries was added to the prepared meringue foam ( $\mathrm{pH} 8$ ), after which the $\mathrm{pH}$ decreased again ( $\mathrm{pH}$ 7). This foam was used to prepare the blue meringues.

\section{Pink meringues (4 servings)}

Utensils:

- bowl, whisks, mixer, $1 \mathrm{dl}$ measuring cup, 1 tablespoon measuring cup, indicator paper, pastry bag, baking tray and parchment paper, pen

Ingredients:

- egg white

- $3 / 4$ dl icing sugar

- $15 \mathrm{ml}$ (3 tbsp.) blueberry juice

- $5 \mathrm{ml}$ (1 tbsp.) lemon juice

Method:

1. Determine the white's $\mathrm{pH}$ with indicator paper. The egg white $\mathrm{pH}$ is

2. Whisk the white into stiff foam with a mixer. Sprinkle in icing sugar near the end of whisking. Continue whisking while sprinkling.

3. Add blueberry juice to prepared meringue foam. Mix.

4. Add $5 \mathrm{ml}$ lemon juice. mix.

5. Determine the prepared meringue foam's $\mathrm{pH}$ with indicator paper. The prepared meringue foam $\mathrm{pH}$ is 
6. Pipe the meringues on the tray.

7. Cook the meringues in an oven at low temperature (approximately $60{ }^{\circ} \mathrm{C}$ ), until they are dry and come off the parchment paper.

Additional information for the teacher:

Additional $5 \mathrm{ml}$ of lemon juice was mixed in the meringue foam containing blueberry juice ( $\mathrm{pH} 7$ ), after which the $\mathrm{pH}$ decreased again ( $\mathrm{pH} 4$ ). This foam was used to prepare the pink meringues.

\subsection{Inquiry based work 2: Different colour red onions}

The inquiry-based work can be performed in 8th or 9th grade chemistry or home economics double class $(2 \times 45 \mathrm{~min})$. This inquiry-based work explores how cooking and different food additives affect red onion's $\mathrm{pH}$ value and colour.

The teacher prepares beforehand or as an opening demonstration three different colour red onions. First, the onions are peeled, sliced and fried gently on a pan. Some sugar and honey is added to the onions. The fried onions are divided in three bowls; vinegar (white wine vinegar, for example) is added to one bowl, baking soda to another and the third one stays as it is. The students compare the appearance of the onions and discuss which one seems appealing and which one does not (Figure 3). The onions are then eaten, with toast for example, and the taste and structure is assessed. Vinegar turns the onion redder while baking soda turns it greenish. Onions fried as they are lose some of their red colour and gain a greyish tone.

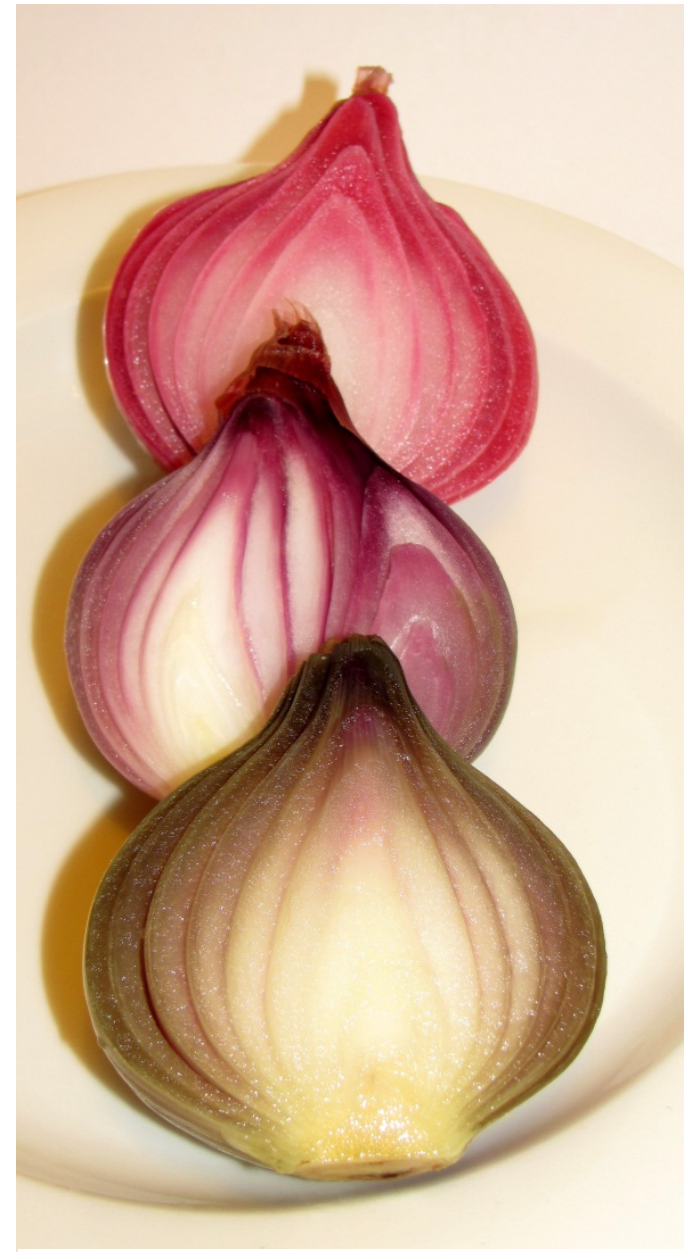

Kuva 3. Different colour red onions.

\section{The chemical background}

The inquiry-based works featured in this article observe the $\mathrm{pH}$ changes during cooking and the discolouration of natural anthocyanin indicators. The chemical background for the phenomena should always be taught according to each grade's curriculum (Finnish National Board of Education, 2003, 2004). 


\subsection{Acids and bases}

A theory by Brønsted and Lowry suggests that acid is a substance that donates the proton $\mathrm{H}^{+}$. Base receives the proton. An acid-base reaction occurs when acid donates the proton to base. Water can act either as an acid or a base in aqueous solution. Oxonium ions $\left(\mathrm{H}_{3} \mathrm{O}^{+}\right)$ form in acids' aqueous solution and hydroxide ions $\left(\mathrm{OH}^{-}\right)$in bases' aqueous solution (Atkins \& J ones, 2002).

The foodstuff in inquiry-based works contain acetic acid, citric acid and the acids in blueberry juice (malic acid etc.); these are all weak organic acids that dissociate only partly in aqueous solution. In the motivational opening demonstration (chapter 2.1), the most acidic drink was achieved with $10 \%$ hydrochloric acid $(\mathrm{HCl})$, a strong acid that dissociates completely in aqueous solution. The discolouration could be achieved practically with acetic acid but it would need a more concentrated solution. The base used in the inquiry-based works is baking soda $\left(\mathrm{NaHCO}_{3}\right)$ which is a weak base.

\section{2. $\mathrm{pH}$ indicators}

Aquetic solutions' acidity is measured with a $\mathrm{pH}$ number. The $\mathrm{pH}$ scale is logarithmically formed of $\mathrm{H}_{3} \mathrm{O}^{+}$concentration:

$$
\mathrm{pH}=-\lg \left[\mathrm{H}_{3} \mathrm{O}^{+}\right] \text {and }\left[\mathrm{H}_{3} \mathrm{O}^{+}\right]=10^{-\mathrm{pH}} \mathrm{mol} / \mathrm{dm}^{3}
$$

When a solution's pH decreases by one unit, the oxonium ion concentration $\left(\left[\mathrm{H}_{3} \mathrm{O}^{+}\right]\right)$ increases tenfold. Clean water has a pH of 7,0 when the temperature is $25^{\circ} \mathrm{C}$.

If a solution's $\mathrm{pH}$ is lower than 7 it is an acidic solution; $\mathrm{pH} 7$ is a neutral solution and if the $\mathrm{pH}$ is higher than 7 it is a basic solution. The $\mathrm{pH}$ can be measured with a $\mathrm{pH}$ gauge, $\mathrm{pH}$ paper or $\mathrm{pH}$ indicator. A solution's acidity can be measured accurately with a pH gauge and quite accurately with $\mathrm{pH}$ paper. With the discolouration of a single indicator it is possible to determine a certain $\mathrm{pH}$ range and if the aqueous solution is in general acidic or basic.

$\mathrm{pH}$ indicators are substances whose colour changes as the solution's acidity changes. Indicators are usually organic weak acids or bases. Indicator molecule's structure changes when it donates or receives a proton. The new structure makes the indicator molecule absorb light at different wavelengths than before; this can usually be observed as a discolouration of the solution (Chandrasekaran, 2001).

Indicators' discolouration range varies. Indicators used in laboratories include phenolphthalein, bromothymol blue (BTS) and pH indicator. Many natural substances also act as indicators. Blue or blue-red berries, vegetables and flowers contain substances known as anthocyanins, which are known to be natural indicators. Blueberry and red onion were used as natural indicators in the works detailed in this article. 


\subsection{Anthocyanins}

Anthocyanin is a common name for water soluble blue-red, blue and red flavonoid pigments in a plant's cell sap. Anthocyanins can be found in blueberry, blackcurrant, raspberry, strawberry, red cabbage, red onion, blue grape and so forth. The word anthocyanin comes from the Greek words anthos, meaning flower, and kyanos, meaning blue. Plants synthesise anthocyanins from sugar and amino acids with the help of sun light. (Hopia, 2008; "Flavonoidien terveysvaikutukset", 2012; Töyrylä, 2012)

\subsubsection{Anthocyanin structure}

There are approximately 500 different known anthocyanins. The large number of different anthocyanins is a result of the diversity of compounds adhering to the main body. The structure of anthocyanins is based on the flavylium ion that has seven possible side groups. Flavylium ion side groups are either plain hydrogens $(-\mathrm{H})$, hydroxide group $(-\mathrm{OH})$ or methoxy groups $\left(-\mathrm{OCH}_{3}\right)$. Anthocyanins contain one or more sugar groups. The sugar groups have a few alternate places in the structure. Sugars adhering to the main body include glucose, galactose, arabinose, rhamnose and rutinose.

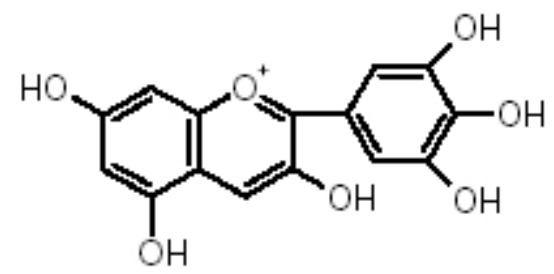

Figure 4. The structure of delphinidin, the anthocyanin in blueberry.

\subsubsection{Anthocyanins as indicators}

Anthocyanin structure changes based on the $\mathrm{pH}$ of the surrounding solution; the colour of the anthocyanins changes as a result. Discolouration from red to blue or green occurs when the solutions change from acidic to basic. Very strong bases may reduce the anthocyanin indicator which causes its colour to turn yellow. The flavylium ion in the anthocyanin structure reacts to the acidity of surrounding solution.

Figure 4 displays the reaction mechanism that the flavylium cation in an anthocyanin goes through when the acidity changes. 


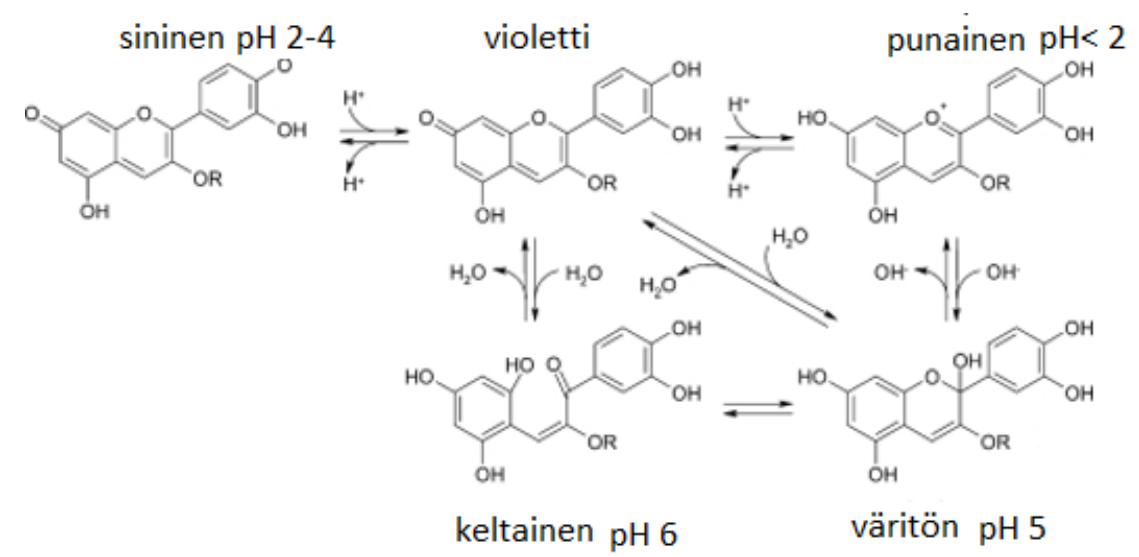

Figure 5. The possible changes in colour and structure of flavylium cation when the solution's acidity changes (based on Barham et al., 2010; Sirkiä, 2013).

\subsubsection{Use of anthocyanins}

Anthocyanins can be used as pigments only to a limit as they are sensitive to changes in $\mathrm{pH}$ values. Discolouration can also be caused by a change in temperature, oxygen or UV radiation. Anthocyanins are not very good at keeping colour so they are only rarely used in colour industry.

In food industry, anthocyanins are mainly used as food dyes: in jams, sweets, drinks (wine for example) and dessert products. The additive code number of anthocyanins in foods is E 163. The cosmetics industry sometimes uses anthocyanins as pigments or antioxidants to prevent and slow the oxidation of cosmetics. (Hintsanen, 2000)

\section{References}

Aroluoma, I., Kanerva, K., Karkela, L., Lampiselkä, J ., Mäkelä, R., Sorjonen, T., \&Vakkilainen, K. (2007). Kemisti 5. Reaktiot ja tasapaino. Helsinki: WSOY.

Atkins, P. \&J ones, L. (2002). Chemistry: Molecules, Matter, and Change. Fourth Edition. W.H. Freeman and Company.

Barham, P., Skibsted, L. H., Bredie, W. L. B., Frøst, M.B., Møller, P., Risbo. J ., ... Mortensen, L. M. (2010). Molecular Gastronomy: A New Emerging Scientific Discipline. Chemical Reviews 110(4), 2313- 2365.

Chandrasekaran, J . (2001). Chemistry of Colours. Resonance: J ournal of Science Education 6(3), 66- 75. Retrieved 9.4.2013 from http:// www.ias.ac.in/ resonance/ Mar2001/ pdf/ Mar2001p6675.pdf

Flavonoidien terveysvaikutukset. (2012). Retrieved 15.5.2012 from http:// www.flavonoidi.com/ antosyaani

Hintsanen, P. (2000). Coloria: Antosyaanit. Retrieved 15.5.2012 from http:// www.coloria.net/ varit/ antosyaanit.htm

Hopia, A. (2008). Kemiaa keittiössä. Helsinki: Nemo.

Finnish National Board of Education. (2003). National core curriculum for upper secondary school 2003. Helsinki: Finnish National Board of Education. 
Finnish National Board of Education. (2004). National core curriculum for comprehensive school 2004. Helsinki: Finnish National Board of Education.

Töyrylä, L. (2012). Argumentaation tukeminen yläasteen happamuuden kemian opetuksessa molekyyligastronomiaa soveltaen. Pro gradu thesis, University of Helsinki, Unit of Chemistry Teacher Education, Department of Chemistry.

Vilhunen, A.-S. (2012). Kehittämistutkimus: Tutkimuksellinen proteiinien opiskelu molekyyligastronomian kontekstissa. Pro gradu thesis, University of Helsinki, Unit of Chemistry Teacher Education, Department of Chemistry. 
MOTTURI ET AL. 